\section{Geografia em avaliações de aprendizagem do ensino médio no Brasil, ENEM (2006 a 2011)}

Daniel Rodriguez de Carvalho

Pinheiro*

Djailson Ricardo Malheiro**

Resumo: Esta pesquisa investiga a frequência e características das questões de Geografia no Exame Nacional de Curso do Ensino Médio entre 2006 e 2011. Tentou-se responder três perguntas: Quantas questões de Geografia ocorreram por prova do ENEM? Quais as palavras-chave de cada questão? Que unidades pedagógicas são deduzíveis desses conjuntos de palavras-chave? O método de pesquisa é exploratório, descritivo, empírico-analítico. E a perspectiva teórica da tarefa da Geografia foi dada por Pitano e Noal (2009) que sustentam que o desafio contemporâneo é investigar a relação sociedade e meiogeográfico. Pretende-se ter mostrado que o ENEM redefine a missão científica da Geografia. A tarefa dela é dar respostas científicas aos problemas, às demandas espaço-temporal humanas e por isso ela tem uma presença muito mais frequente no ENEM do que nas aulas do ensino médio.

\section{Geography in assessments of learning high school in Brazil, ENEM (2006 to 2011)}

\begin{abstract}
This study investigates the frequency and characteristics of Geography questions in the National High School Exam between 2006 and 2011. We tried to answer three questions: How many Geography questions were there in each ENEM exam? What are the keywords of each question? What pedagogical units are deductible in these sets of keywords? The research methods are the exploratory, descriptive and empirical-analytic. And the theoretical perspective of the Geography task was given by Pitano and Noal (2009) who defend that the contemporary challenge is to investigate the relationship between society and geographical environment. The aim is to have shown that ENEM redefines the mission of scientific geography. Its task is to give scientific answers to the problems and to human spatiotemporal demands. That's why Geography has a much more frequency on ENEM than in high school classes.
\end{abstract}

* Arquiteto, Urbanista, Professor do Programa de Pós-Graduação em Geografia da Universidade Estadual do Ceará; Professor Titular da Universidade de Fortaleza.

** Geógrafo, Professor de Ecologia na Faculdade de Medicina Estácio de Juazeiro do Norte.

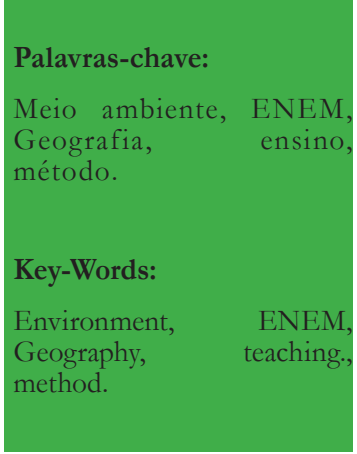




\section{Introdução}

Um dos principais desafios do ensino de Geografia nas escolas é responder a pergunta: o que ensinar? Para as escolas, há mais de uma fonte onde as respostas devem ser buscadas. Dentre elas, destacam-se três:

a) Os parâmetros curriculares nacionais para o ensino médio: ciências humanas e suas tecnologias (PCNEM)de autoria da Secretaria de Educação Média e Tecnológica, órgão do Ministério da Educação do Brasil (SEMT, 2000);

b) As diretrizes curriculares para o ensino médio editadas pelas secretarias de educação do ensino fundamental e médio dos estados brasileiros;

c) E as provas do Exame Nacional do Ensino Médio (ENEM), uma prova padronizada que avalia o ensino médio brasileiro, que está substituindo os exames vestibulares das universidades públicas e, na prática, cria uma classificação (ranking) das escolas pública e privadas brasileiras.

Do ponto de vista da gestão do ensino, o ENEM é um documento importante. Ele sinaliza objetivamente o que um estudante deve saber para passar nos exames de boas universidades brasileiras.

O problema parte da pesquisa, portanto, é saber com que frequência as questões de Geografia aparecem nos exames do ENEM? Qual é o assunto predominante ou o que o estudante deve que saber?

O objetivo da pesquisa foi investigar qual a importância estatística da Geografia no Exame Nacional do Ensino Médio entre 2006 e 2011.

A pesquisa pretende mostrar que a Geografia está muito mais presente nesse exame do que se poderia imaginar. Está presente até mesmo em questões de biologia e química.

\section{Métodos de pesquisa}

Esta pesquisa é qualiquantitativa, exploratória e descritiva. Foi feita com a intenção de orientar o ensino de Geografia nas escolas de primeiro e segundo graus (RICHARDSON, 1999). E por depender de interpretação (CORETH, 1973) de informações de estatística descritiva, trata-se de uma pesquisa empírico-analítica (HABERMAS, 1987).

O período de exames foram os anos de 2006 a 2011, dois triênios, como se faz nas avaliações da CAPES - Coordenação de Aperfeiçoamento de Pessoal de Nível Superior.

Supôs-se que o ENEM é uma tecnológica avaliação em desenvolvimento. Por essa razão, as provas dos exames de 1998 a 2005 não foram incluídas na pesquisa. Preferiu-se as provas tecnologicamente mais desenvolvidas.

\section{As fontes de informação}

Em 2006, o ENEM teve 3,7 milhões de inscritos (MEC, 2006). Em 2012, o ENEM teve mais de 6,4 milhões de inscritos (VEJA, 2012). Portanto, o impacto na vida dos estudantes foi suficientemente importante para se tentar responder às seguintes perguntas:

Geografia Ensino \& Pesquisa, v. 17, n.3, p. $115-126$, maio/ago. 2013

Geografia em avaliações de aprendizagem do ensino médio no Brasil, ENEM (2006 a 2011) a) Quantas questões de Geografia ocorreram por prova do ENEM?

b) Quais as palavras-chave recorrentes de cada questão?

c) Que unidades pedagógicas são deduzíveis desses conjuntos de palavras-chave?

As provas fraudadas de 2009 não foram examinadas para que não houvesse excesso de questões no ano base 2009. Embora se reconheça que do ponto de vista do planejamento de disciplina seria interessante inclui-las. 


\section{O tratamento dos dados e informações}

Em princípio haveria duas possibilidades de tratar as informações obtidas daquele modo:

a) reuni-las num arranjo de categorias por identidade estatística (covariâncias) a partir de uma análise multivariada;

b) ou reuni-las por unidade de planejamento de aula por intuição intelectual.

A análise multivariada seria cientificamente mais apropriada. Entretanto, seria preciso que houvesse cinco vezes mais provas do ENEM que o número de categorias que as palavras-chave indicavam (HAIR e outros 2009; FIELD, 2003). Ou provas do ENEM pelo menos aplicadas nos últimos 60 anos. Sendo assim, esse método não poderia ser usado.

A segunda possibilidade é mais subjetiva: organizar as categorias por unidades de conhecimento numa tabela de frequência em que as palavras-chave que representassem fatores apareceriam e as variáveis seriam subsumidas, salvo aquelas variáveis que não pareceriam reunidas em fatores. Isso é muito subjetivo. Mas parece a única possibilidade. O intervalo de tempo de existência do ENEM e número de provas são estatisticamente inexpressivos.

As unidades de conhecimento da Geografia foram tiradas do drops da área de Geografia elaborado pelo sistema Lattes do CNPq e seus colaboradores. A área de Geografia do Meio Ambiente e da Saúde não está no sistema Lattes. Ela aparece no quadro de unidades pedagógicas por exigência da pesquisa.

As subáreas denominadas pelo Lattes de Geografia Regional, Análise Regional e Regionalização foram reunidas numa única célula do quadro estruturado em razão da dificuldade de separá-las nesse tipo de exame: o ENEM. E em razão das próprias questões de prova, foi incluída a Cartografia.

Essas tabelas, embora sejam recursos simples, contribuíram para responder a pergunta: o que o professor de Geografia deve ensinar para o estudante obter resultados médios no ENEM?

\section{Critérios de inclusão}

O critério de inclusão de uma determinada questão no campo de conhecimento geográfico seguiu um protocolo simples. Era bastante que ocorresse uma das seguintes situações:

a) a questão foi elaborada a partir de citação de um geógrafo;

b) a questão foi proposta a partir de publicação da Geografia;

c) entre as palavras-chave da questão, pelo menos uma é palavra-chave da Geografia;

d) no entendimento do leitor, aquele assunto da questão em exame está previsto pelo ensino de Geografia (SEMT, 2002), mesmo que compartilhado com outra matéria, como a História.

\section{Caracterização das provas do ENEM}

Geografia Ensino \& Pesquisa, v. 17, n.3, p. 115-126, maio/ago. 2013.

O objetivo dessa seção é mostrar que as questões do ENEM, de 1998 a 2011, tendem a depender mais de compreensão e interpretação de texto ou texto e figuras para ser solucionadas. E menos da memorização.
Pinheiro, D. R. de C.; Malheiro, D. R. 
As provas do ENEM começam a ser feitas em 1998. Elas fazem parte de um conjunto de sistemas de avaliação da educação brasileira que surgiram no bojo das políticas do ministro da educação Prof. Paulo Renato de Souza.

Ao longo dos últimos 15 anos, a tecnologia de avaliação passou por variações e crises, como as fraude que ocorreram em 2009, que implicaram refazer e reimprimir as provas daquele ano.

Em 1998, havia uma única prova de 63 questões que abrangiam os conhecimentos de:ciências humanas e suas tecnologias; ciências da natureza matemática e suas tecnologias; linguagem, códigos e suas tecnologias.

Admitindo-se que a solução de cada questão é uma conduta com objetivos. Admitiu-se que haveria três grupos de objetivos ${ }^{1}$. Seriam:

A1) ler, entender e identificar elementos da teoria.

B1) compreender, interpretar textos a partir da teoria e deduzir a resposta;

C1) compreender, interpretar textos e figuras a partir da teoria e deduzir a resposta.

As questões mais fáceis seriam aquelas que dependem de:

A2) conhecer uma definição ou saber aplicar uma fórmula a exemplo das questões 1, 6, 7, 9, 10, 11 da prova de 1998.

As questões mais trabalhosas implicariam:

B2) explicitar o sentido, estabelecer correlações, entender processos;

C2) explicitar o sentido, estabelecer correlações, entender processos e deduzir enunciados explicativos e às vezes entender o que o examinador quer que ele responda.

Em 1998, 40\% das questões do ENEM dependiam mais de memória que de interpretação e $60 \%$ dependiam de interpretação de textos e/ou figuras (Tabela 1).

Tabela 1 - Da natureza e frequências das respostas às questões do ENEM de 1998.

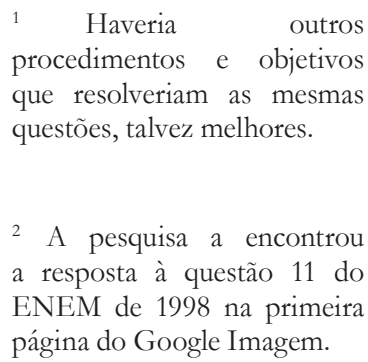

página do Google Imagem.

\begin{tabular}{|c|c|c|c|}
\hline Objetivas da examinanda & $\begin{array}{l}\text { Númera de questäes } \\
\text { cam as mesmas } \\
\text { abjetivas par prava. }\end{array}$ & Per cent agem & $\begin{array}{c}\text { Natureza das vidências em favor } \\
\text { da resposta correta }\end{array}$ \\
\hline $\begin{array}{l}\text { Ler, entender e identificar } \\
\text { el ementos da teoria. }\end{array}$ & $25 / 63$ & $40 \%$ & $\begin{array}{l}\text { Exemplo. Definição. Aplicação de } \\
\text { fórmulas. }\end{array}$ \\
\hline $\begin{array}{c}\text { Compreender, interpretar textos } \\
\text { a patir da teoria e deduzir a } \\
\text { resposta. }\end{array}$ & $27 / 63$ & $43 \%$ & $\begin{array}{l}\text { Explicitar o sentido. Estabelecer } \\
\text { correlaçốes. Entender processos. }\end{array}$ \\
\hline $\begin{array}{l}\text { Compreender, interpretar textos } \\
\text { e figuras a partir da teoriae } \\
\text { deduzir a resposta. }\end{array}$ & $11 / 63$ & $17 \%$ & $\begin{array}{l}\text { Explicitar o sentido. Estabelecer } \\
\text { correlaốes. Entender processos } \\
\text { Deduzir enunciados explic tivos. }\end{array}$ \\
\hline Total & 63 questäes & $100 \%$ & \\
\hline
\end{tabular}

Fonte: pesquisa direta.

A questão 11 da prova do ENEM de 1998, por exemplo, foi classificada como

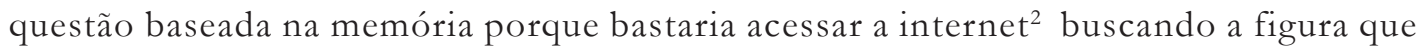
a ilustra e a resposta é imediata e baseada na definição. 
Questão 11. Na figura abaixo está esquematizado um tipo de usina utilizada na geração de eletricidade.

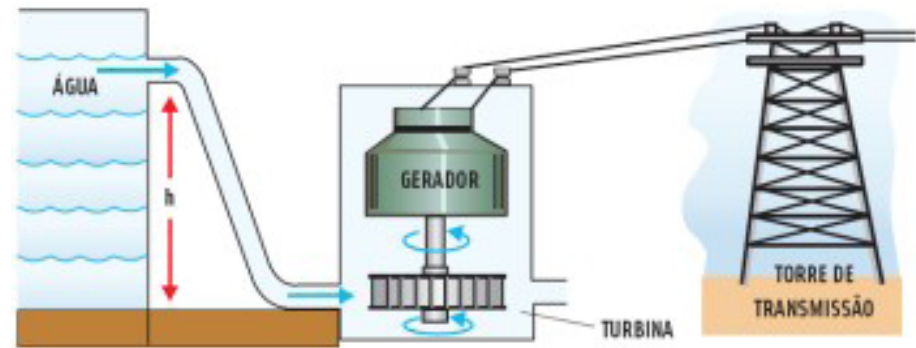

Analisando o esquema, épossivel identificar que se trata de uma usina:

(A) hidrelétrica, porque a água corrente baixa a temperatura da turbina.

(B) hidrelétrica, porque a usina faz uso da energia cinética da água.

(C) termoelétrica, porque no movimento das turbinas ocorre aquecimento.

(D) eólica, porque a turbina é movida pelo movimento da água.

(E) nuclear, porque a energia é obtida do núcleo das moléculas de água.

No início, ainda havia muitas questões abstratas, que exigiam reflexões mais complexas e entender onde o examinador queria chegar, por exemplo, a questão 44 da prova de 1998 que teria mais de uma resposta correta.O critério para a escolha do tema da oficina foi precedido de pesquisa realizada nas escolas Estaduais de Buritizeiro, (E. E. José Maria Pereira) e Pirapora/ MG, (E. E. Fernão Dias; E. E. Coronel Ramos e a E. E. Argelci Motta) junto aos docentes da disciplina geografia das mencionadas instituições. Foram os professores que informaram, mediante entrevista, quais conteúdos consideravam mais críticos, carentes de reforço escolar devido a baixa produtividade dos alunos verificada através de avaliações e participação. A maioria dos professores apontou a Cartografia.

Questão 44. Um dos fenômenos mais discutidos e polêmicos da atualidade é a "Globalização", a qual impacta de forma negativa:

(A) na mão-de-obra desqualificada, desacelerando o fluxo migratório.

(B) nos países subdesenvolvidos, aumentando o crescimento populacional.

(C) no desenvolvimento econômico dos países industrializados desenvolvidos.

(D) nos países subdesenvolvidos, provocando o fenômeno da "exclusão social".

(E) na mão-de-obra qualificada, proporcionando o crescimento de ofertas de emprego e fazendo os salários caírem vertiginosamente.

Para o INEP a resposta certa seria a " $D$ ", mas a queda de salários dos trabalhadores qualificados é um fenômeno descrito em bases de dados importantes como o CAGED. Isso significaria que a resposta correta seria a "E". A exclusão social tem fatores históricos associados a ela bem anteriores à Globalização da segunda metade do século XX.

Essas questões abstratas e / ou baseadas em informações gerais ainda eram recorrentes até 2005. Embora fossem cada vez mais incomuns, à medida que o modelo de avaliação amadurecia.

\section{Característica das questões do ENEM em 2011}

Em 2011, predominam as questões que depende de explicitar o sentido, estabelecer correlações, entender processos, deduzir enunciados explicativos. Para ser exato, só $2 \%$ das questões dependiam apenas de boa memória.

Geografia Ensino \& Pesquisa, v. 17, n.3, p. 115-126, maio/ago. 2013.

Pinheiro, D. R. de C.; Malheiro, D. R.

ISSN 2236-4994 I $\quad 119$ 
internet. Entrementes, $67 \%$ dependiam da capacidade de compreender e interpretar textos. E $31 \%$ dependiam também de interpretar figura, algumas bem complexas como a utilizada na questão de Geografia número 44 (ver comentários adiante).

Tabela 2 - Tabela da natureza e frequências das respostas às questões do ENEM de 2011.

\begin{tabular}{|c|c|c|c|c|}
\hline \multirow{2}{*}{ Objetivos da examinanda. } & \multirow{2}{*}{$\begin{array}{l}\text { Númera de questies } \\
\text { com as mesmas } \\
\text { abjetivas pur prava. }\end{array}$} & \multicolumn{2}{|c|}{ Percentagem } & \multirow{2}{*}{$\begin{array}{c}\text { Naturean das vidências em favor } \\
\text { da resposta carreta }\end{array}$} \\
\hline & & 2011 & 1998 & \\
\hline $\begin{array}{l}\text { Ler, entender e identificar } \\
\text { elementos da teoria. }\end{array}$ & $2 / 90$ & $2 \%$ & $40 \%$ & $\begin{array}{c}\text { Exemplo. Definição. Aplicação de } \\
\text { fórmulas. }\end{array}$ \\
\hline $\begin{array}{c}\text { Compreender, interpretar textos } \\
\text { a partir da teoria e deduzir a } \\
\text { resposta. }\end{array}$ & $60 / 90$ & $67 \%$ & $43 \%$ & $\begin{array}{l}\text { Explicitar o sentido. Estabelecer } \\
\text { correlações. Entender processos. }\end{array}$ \\
\hline $\begin{array}{l}\text { Compreender, interpretar textos } \\
\text { e figuras a partir da teoria e } \\
\text { deduzir a resposta. }\end{array}$ & $28 / 90$ & $31 \%$ & $17 \%$ & $\begin{array}{l}\text { Explicitar o sentido. Estabelecer } \\
\text { correlações. Entender processos } \\
\text { Deduzir enunciados explicativos. }\end{array}$ \\
\hline
\end{tabular}

Fonte: pesquisa direta.

Considerando os objetivos do estudante que fez a prova do ENEM de 2011, poder-se-ia dizer que as questões que dependem de exemplo, memorização de definição, e aplicação de fórmulas que eram $40 \%$ da prova em 1998 , passaram a $2 \%$ da prova em 2011. Alguns exemplos ajudam a entender a evolução da prova.

Para dar a resposta correta à maioria das questões do ENEM de 2011, o

${ }^{3}$ Não encontramos nenhuma pesquisa científica que mostrasse que expectativa de vida ao nascer é menor entre os moradores de São Paulo que costumam andar de bicicleta. Mas há muitas pesquisas científicas que mostram que a expectativa de vida ao nascer aumenta em até 10 anos para quem faz exercícios regulares como o personagem da matéria.

Encontramos todas as figuras da prova do ENEM de 2011 na internet.

Geografia Ensino \& Pesquisa, v. 17, n.3, p. 115-126, maio/ago. 2013

Geografia em avaliações de aprendizagem do ensino médio no Brasil, ENEM (2006 a 2011) examinando teria que relacionar pelo menos dois enunciados a uma única resposta apropriada. A questão 10 é um exemplo interessante.

Questão10. Enunciado 17 O professor Paulo Saldiva pedala $6 \mathrm{~km} \mathrm{em} 22$ minutos de casa para o trabalho, todos os dias. Nunca foi atingido por um carro. Mesmo assim, é vítima diária do trânsito de São Paulo: a cada minuto sobre a bicicleta, seus pulmões são envenenados com 3,3 microgramas de poluição particulada poeira, fumaça, fuligem, partículas de metal em suspensão, sulfatos, nitratos, carbono, compostos orgânicos e outras substâncias nocivas. ESCOBAR, H. Sem Ar. O Estado de São Paulo. Ago. 2008.

Enunciado 27 A população de uma metrópole brasileira que vive nas mesmas condições socioambientais das do professor citado no texto apresentará uma tendência de

(A) ampliação da taxa de fecundidade.

(B) diminuição da expectativa de vida. [Enunciado 37

(C) elevação do crescimento vegetativo.

(D) aumento na participação relativa de idoso.

(E) redução na proporção de jovens na sociedade.

Para o INEP, a resposta correta era a B. Isso deve significar que uma pessoa como o personagem da matéria que anda de bicicleta numa metrópole com um ar contaminado como o da cidade de São Paulo tem a expectativa de vida [suponho que seja ao nascer] diminuída [mas não sei em relação a que grupo. Talvez seja menor do que a expectativa de vida de outros paulistanos. Talvez de outros professores também usuários de bicicleta] ${ }^{3}$. Mas essa inconsistência da pergunta em nada altera a natureza filosófica do raciocínio.

Algumas questões dependiam de noção razoável de cartografia e de relacionar mais de quatro enunciados à resposta correta. Um exemplo de figura ${ }^{4}$ copiada da internet a ser interpretada encontra-se na questão 44, Prova Amarela do ENEM de 2011. 
Questão 44. [Enunciado 1] Nova desordem geográfica mundial: uma proposta de regionalizaçãa

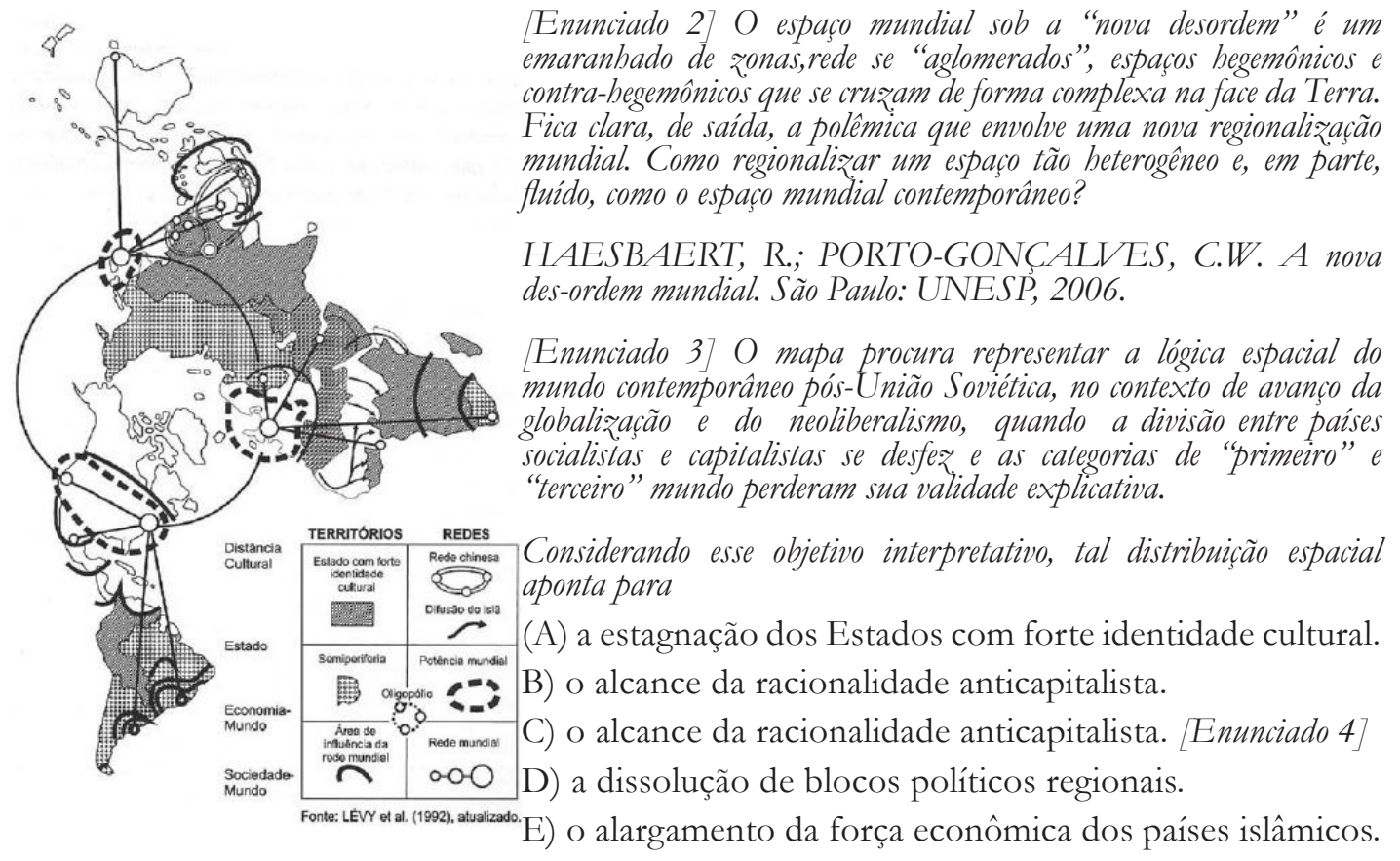

A questão 44, como outras que recorrem à figuras, associam-se quatro enunciados e não três, como nos casos em que não há figuras.

\section{Descrição das unidades de conhecimento mais frequentes em avaliações de aprendizagem do ENEM}

O objetivo desta seção é caracterizar as provas do ENEM do ponto de vista da Ciência Geográfica (2006 a 2011). Do ponto de vista da frequência das questões de Geografia por prova, têm-se as seguintes características:

a) As evidências empíricas mostram que a Geografia tem uma presença muito forte nas provas do ENEM, chegando a ser 48\% de uma prova que inclui conhecimentos de Geografia, Filosofia, História e Sociologia e suas tecnologias (tabela 3).

b) $\mathrm{O}$ ano em que houve menos questões do ENEM na área da Geografia foi 2010. Apenas 14\% de uma prova de Geografia, Filosofia, História e Sociologia. Em todos os outros anos, a Geografia é pelo menos $1 / 4$ da prova e até $1 / 2$ da prova (tabela 3 ).

c) A subárea ou unidade pedagógica mais demandada (tabelas 3 e 4) foi a Geografia do Ambiente e da Saúde (LACAZ; BARUZZI; SIQUEIRA, 1972; PITANO; NOAL, 2009);

Essa demanda ambiental parece corresponder a uma nova perspectiva teórica sintetizada por Pitano e Noal (2009, p. 1) nos seguintes termos:

Entendemos que, se o fator determinante para o esgotamento dos elementos vitais do meio geográfico e das condições de sustentabilidade da vida na terra é o resultado das relações estabelecidas entre os homens, em sistemas sociais culturalmente heterogêneos, precisamos modificar nossa perspectiva de análise diante dos problemas ambientais na educação. $O$ foco passa a ser não mais a dinâmica ser humano $x$ natureza ou, ainda, sociedade x natureza, e sim sociedade $\mathrm{x}$ meio geográfico, o que sugere uma educação "socioambiental". (Grifos nossos)

Geografia Ensino \& Pesquisa, v. 17, n.3, p. 115-126, maio/ago. 2013.

Pinheiro, D. R. de C.; Malheiro, D. R. 
A natureza do espaço é historicamente situada (SANTOS, 2002), por isso, o ENEM redefiniu o "horizonte de sentido" (OLIVEIRA, 1987, p. 2) apontando para a perspectiva socioambiental (MENDONÇA, 1994) que, em tese, é mais especificamente contemporânea que o ponto de vista antroambiental (ou se preferir, espaço antrópico homem-natureza).

d) E a unidade pedagógica sem demanda alguma é a Teoria do Desenvolvimento Regional (Tabela 3 e Tabela 4);

Tabela 3 - Ocorrência das questões de Geografia por unidade pedagógica, por palavra-chave e por questão das provas do ENEM.

Geografia Ensino \& Pesquisa, v. 17, n.3, p. 115-126, maio/ago. 2013

Geografia em avaliações de aprendizagem do ensino médio no Brasil, ENEM (2006 a 2011)

\begin{tabular}{|c|c|c|c|c|c|c|c|c|}
\hline \multirow{2}{*}{ Area } & \multirow{2}{*}{ Unidade Pedagógica } & \multirow{2}{*}{$\begin{array}{l}\text { Pal avras-chave } \\
\text { características }\end{array}$} & \multicolumn{6}{|c|}{$\begin{array}{l}\text { Número relativo de questões que exigem de } \\
\text { Geografia por número de questão da prova }\end{array}$} \\
\hline & & & 2006 & 2007 & 2008 & 2009 & 2010 & 2011 \\
\hline \multirow{14}{*}{ 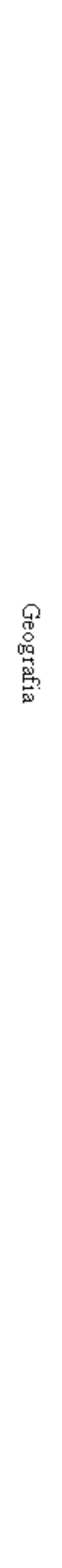 } & $\begin{array}{l}\text { I Geografia da } \\
\text { Cultura }\end{array}$ & Religião & 0 & $1 / 63$ & 0 & $1 / 90$ & 0 & $1 / 90$ \\
\hline & $\begin{array}{l}\text { II Geografia } \\
\text { Econômica }\end{array}$ & $\begin{array}{c}\text { Arabe. } \\
\text { Industrialização. } \\
\text { Combustíveis. } \\
\text { Cadeia de produção. } \\
\text { Trabalho }\end{array}$ & $1 / 63$ & $3 / 63$ & $1 / 63$ & $1 / 90$ & 0 & $3 / 90$ \\
\hline & $\begin{array}{l}\text { III Geografia } \\
\text { Agrária }\end{array}$ & $\begin{array}{c}\text { Extrativismo. } \\
\text { Cultivo. Tecnologia } \\
\text { Agrárias. } \\
\text { Modernização }\end{array}$ & $1 / 63$ & $1 / 63$ & $2 / 63$ & $5 / 90$ & $4 / 90$ & $1 / 90$ \\
\hline & $\begin{array}{l}\text { IV Geografia da } \\
\text { População }\end{array}$ & Migração. & $4 / 63$ & 0 & $5 / 63$ & $1 / 90$ & 0 & $3 / 90$ \\
\hline & V Geografia Política & $\begin{array}{c}\text { Conflitos } \\
\text { internacionais. } \\
\text { Arabes. G20. } \\
\text { OTAN. }\end{array}$ & 0 & 0 & 2 & $4 / 90$ & $1 / 90$ & $0 / 90$ \\
\hline & $\begin{array}{l}\text { VI Geografia } \\
\text { Urbana }\end{array}$ & $\begin{array}{l}\text { Urbanização. } \\
\text { Planejamento. } \\
\text { Território. } \\
\text { Globalização. }\end{array}$ & $1 / 63$ & 0 & 0 & $4 / 90$ & 0 & $1 / 90$ \\
\hline & $\begin{array}{c}\text { VII Geografia } \\
\text { Regional, Análise } \\
\text { Regional, } \\
\text { Regionalização }\end{array}$ & $\begin{array}{c}\text { Regionalização. } \\
\text { Amazônia. Centro- } \\
\text { Oeste. }\end{array}$ & 0 & 0 & 0 & 0 & 0 & $4 / 90$ \\
\hline & $\begin{array}{c}\text { VII Teoria do } \\
\text { Desenvolvimento } \\
\text { Regional }\end{array}$ & - & 0 & 0 & 0 & 0 & 0 & 0 \\
\hline & $\begin{array}{c}\text { DX Geografia } \\
\text { Ambiental e } \\
\text { Geografia da Saúde. }\end{array}$ & $\begin{array}{l}\text { Clima. Degradação. } \\
\text { Floresta Calor. } \\
\text { Poluição. Legislação } \\
\text { Ambiental. Solo. }\end{array}$ & $12 / 63$ & $22 / 63$ & $19 / 63$ & $16 / 90$ & $6 / 90$ & $7 / 90$ \\
\hline & X Cartografia. & $\begin{array}{l}\text { Coordenadas } \\
\text { geográfica. }\end{array}$ & $1 / 63$ & 0 & 0 & 0 & $1 / 90$ & 0 \\
\hline & XI Geomorfologia & $\begin{array}{c}\text { Pedogênese. Bioma. } \\
\text { Sistema ambiental. } \\
\text { Rochas. }\end{array}$ & $9 / 63$ & 0 & 0 & 0 & $1 / 90$ & 0 \\
\hline & $\begin{array}{l}\text { Total de questões } \\
\text { pelo número de } \\
\text { questóes da prova }\end{array}$ & & $28 / 63$ & $30 / 63$ & $27 / 63$ & $32 / 90$ & $13 / 90$ & $21 / 90$ \\
\hline & $\begin{array}{l}\text { Participação da } \\
\text { Geografia na prova } \\
\text { de Ciências }\end{array}$ & & $44 \%$ & $48 \%$ & $43 \%$ & $35 \%$ & $14 \%$ & $23 \%$ \\
\hline & Humanas & & & & & & & \\
\hline
\end{tabular}

Fonte: pesquisa direta. 
Tabela 4 - Frequências das questões de Geografia por unidade pedagógica.

\begin{tabular}{|c|c|c|}
\hline Unidade Pedagúgica & $\begin{array}{l}\text { Nümera absoluta de questōes de Geogr afia } \\
\text { pur prava da ENEM entre } 2006 \text { a } 2011\end{array}$ & Percertagem \\
\hline I Geografia da Cultura & $\mathbf{3}$ questões & $2 \%$ \\
\hline II Geografia Econômica & $\mathbf{8}$ questões & $7 \%$ \\
\hline III Geografia Agrária & 14 questões & $12 \%$ \\
\hline IV Geo grafia da População & 13 questões & $11 \%$ \\
\hline V Geografia Politica & 5 questões & $4 \%$ \\
\hline VI Geografia Urbana & 6 questões & $\mathbf{5} \%$ \\
\hline $\begin{array}{l}\text { VI Geografia Regional, Análise } \\
\text { Regional, Regionalização. }\end{array}$ & 4 questões & $4 \%$ \\
\hline $\begin{array}{l}\text { VIII } \mathrm{T} \text { eoria do Desenvolvimento } \\
\text { Regional }\end{array}$ & 0 & 0 \\
\hline $\begin{array}{c}\text { IX Geografia Ambiental e Geografia } \\
\text { da Saúde. }\end{array}$ & $\mathbf{5 3}$ questões & $45 \%$ \\
\hline $\mathrm{X}$ Cartografia. & 2 questões & $2 \%$ \\
\hline XI Geomorfologia & 10 questões & $8 \%$ \\
\hline Somatório das frequências & 118 questões & $100 \%$ \\
\hline
\end{tabular}

Fonte: pesquisa direta.

e) Em todos os casos, as questões de geografia foram sempre mais frequentes do que as horas-aulas de Geografia numa escola de referência;

Para chegar ao colégio de referência escolheu-se um critério: o número de estudantes aprovados no vestibular do ITA, Instituto Tecnológico da Aeronáutica, pois se trata de uma seleção muito disputada e de que participam alunos de todas as escolas do Brasil.

O Portal G1 (2012) da Rede Globo publicou uma matéria com o seguinte título: " $34 \%$ dos aprovados no ITA são estudantes de escolas do Ceará". Esse não foi um desempenho esporádico. Um grupo de três escolas tem aprovado muitos alunos no ITA (Instituto Tecnológico da Aeronáutica) e no IME (Instituto Militar de Engenharia) desde os anos de 1990. Portanto, a escola de referência é a síntese de três escolas de fato.

Em 1998, nessas três escolas particulares, estudava-se 2 horas-aulas de Geografia por semana. O bloco da Matemática, Física, Química e Biologia era no mínimo 16 horas-aulas por semana. História, 2 horas-aulas. Língua Portuguesa, 4 horas aulas. Portanto, a Geografia representada em média 1/8 horas-aulas semanais.

f) A pior situação, o ano de 2010, a Geografia foi da prova;

g) O ano de maior presença pela Geografia (2007), ela foi da prova do ENEM;

h) Mas a Geografia é apenas das horas-aulas semanais das três escolas de referência.

Portanto, considerando os achados “f”, “g”, "h", pode-se afirmar que os estudantes que fazem ENEM têm relativamente bem mais questões de prova que aulas de Geografia.

Geografia Ensino \& Pesquisa, v. 17, n.3, p. 115-126, maio/ago. 2013.

Pinheiro, D. R. de C.; Malheiro, D. R.

i) Outro achado interessante foi ocorrência de perguntas cujas respostas exigiam 
um conhecimento básico da legislação ambiental, com destaque para a Lei dos Crimes Ambientais (BRASIL, 1998) e Estatuto das Cidades (BRASIL, 2001).

Entretanto, essa ocorrência exige um trabalho específico de investigação da ocorrência de pergunta referente à legislação ambiental no ENEM.

A Tabela 4 mostra duas coisas preocupantes:

j) Não há questões de Teoria do Desenvolvimento Regional (Tabela 4).

Isso talvez reflita o fim dos organismos federais de desenvolvimento regional como a SUDENE, SUDAM, BASA, FINOR entre outros.

k) E a frequência com que são cobrados conhecimentos de Geografia da Cultura é muito pequena (Tabela 4).

Talvez seja uma ocorrência associada às características epistemológicas e teóricas da área, muito dependentes de métodos histórico-hermenêuticos (CRETH, 1973), e a dificuldade de elaborar questões objetivas de Geografia da Cultura.

\section{Considerações finais}

A leitura das provas do ENEM mostra uma abordagem de avaliação cada vez mais comum: em vez de perguntar por conceitos, definições, leis naturais, normas ou aplicar diretamente uma fórmula ou algoritmo, pede-se que o estudante examine, interprete e / ou resolva um problema da vida comum recorrendo à teoria.

A caracterização rápida e geral das questões de Geografia leva a um resultado interessante: a redefinição estratégica da Geografia. Noutros termos, o ENEM redefine a missão científica das ciências geográficas. A tarefa da Geografia é dar respostas científicas aos problemas socioespacial-temporal. Portanto, a Geografia é uma ciência empírico-analítica ou histórico-hermenêutica (CORETH, 1973) e não somente um saber responsável e comunicável.

Se essa interpretação estiver correta, o ensino de Geografia deve estar mais focado em entender qual o sentido do meio geográfico. Para sustentar essa ideia, mostrou-se que as questões de Geografia do ENEM não perguntam mais por dados, informações ou definições. Isso se poderia ser encontrado pronto na web. As questões de Geografia perguntam pelo sentido das informações e teorias.

A Geografia que deve ser ensinada, considerando-se a natureza epistemológica das perguntas do ENEM, é uma Geografia científica, metódica, sistemática e crítica. Portanto, trata-se de um horizonte de sentido amplo e historicamente situado. Parece que isso é diferente de ser apenas crítica. Uma boa crítica não precisa ser científica.

Numa palavra, as questões de Geografia são solucionáveis quando o examinando tem uma boa leitura e desenvolveu uma razoável capacidade de pensar cientificamente.

Entretanto, uma pesquisa exploratória tem suas limitações. A interpretação

Geografia Ensino \& Pesquisa, v. 17, n.3, p. $115-126$, maio/ago. 2013

Geografia em avaliações de aprendizagem do ensino médio no Brasil, ENEM (2006 a 2011) é uma ação muito subjetiva, mas o ENEM não é um evento local ou regional. $O$ ENEM é um evento nacional. E as evidências empíricas apontam para uma boa nova: a Geografia está ocupando seu lugar entre as ciências de base. Conhecer Geografia é um portal de sucesso do estudante brasileiro. 


\section{Referências}

AUSUBEL, David. Psicologia educacional. Rio de Janeiro: Inrteramericana, 1980.

BRASIL. Lei no 10.257, de 10 de julho de 2001 (Estatuto das Cidades). Disponível em:<http://www.planalto.gov.br/ccivil/leis/LEIS_2001/L10257. htm $>$ acesso em 28 de maio de $2011 \mathrm{c}$;

BRASIL. Lei no 9605, de 12 de fevereiro de 1998 (Lei dos Crimes Ambientais). Disponível em<http://www.planalto.gov.br/ccivil_03/Leis/L9605.htm> acesso em 28 de maio de 2012

CORETH, Emerich. Questões fundamentais de hermenêutica. São Paulo: EPU, 1973;

FIEL, Andy. Descobrindo a estatística usando o SPSS. Porto Alegre: Bookman, Artmed, 2003.

HABERMAS, Jürgen. Dialética e hermenêutica: para a crítica da hermenêutica de Gadamer. Porto Alegre: L\&PM, 1987.

HAIR Jr., Josph F. e outros. Análise multivariada de dados. Porto Alegre: Bookman, 2009

LACAZ; Carlos da Silva; BARUZZI; Roberto G.; SIQUEIRA Júnior, Waldomiro. Introdução à geografia médica do Brasil. São Paulo: Editora da Universidade de São Paulo, 1972

MEC. Enem 2006 tem 3,7 milhões de inscritos [21 de agosto de 2006]. Disponível em: http://portal.mec.gov.br/index.php?option=com content\&task=view\&id=6866 Acessado em: 25 dez. 2012.

MENDONÇA, Francisco de Assis. Geografia e meio ambiente. São Paulo: Contexto, 1994

OLIVEIRA, Manfredo Araújo de. Conhecimento e Historicidade. Revista Síntese Nova Fase, n. 40, 1987, p. 34. 161;

PITANO, Sandro de C.; NOAL, Rosa Elena. Horizontes de diálogo em Educação Ambiental: contribuições de Milton Santos, Jean-Jacques Rousseau e Paulo Freire. Educação em Revista,Belo Horizonte, v. 25, n. 3, dez. 2009 . Disponível em: http://www.scielo.br/scielo.php?pid=S010246982009000300014\&script=sci_arttext Acesso: 26 dez. 2012

SANTOS, Milton. A natureza do espaço. São Paulo: Edusp, 2002.

SEMT -SECRETARIA DE EDUCAÇÃO MÉDIA E TECNOLÓGICA. Os parâmetros curriculares nacionais: ensino médio, ciências humanas e suas tecnologias. Disponível em: http://portal.mec.gov.br/seb/arquivos/pdf/ cienciah.pdf Acessado em: 14 dez. 2012 [2000].

VEJA[on-line]. Enem 2012 tem mais de 6,4 milhões de inscritos. Disponível em: http://veja.abril.com.br/noticia/educacao/enem-tem-mais-de-6-4milhoes-de-inscritos Acessado em 25 dez. 2012.

Geografia Ensino \& Pesquisa, v. 17, n.3, p. 115-126, maio/ago. 2013.

Pinheiro, D. R. de C.; Malheiro, D. R. 


\section{Correspondência:}

Daniel Rodriguez de Carvalho Pinheiro - Universidade Estadual do Ceará, Centro de Ciências e Tecnologia, Programa de Pós-Graduação em Geografia. Avenida Paranjana, 1700, CEP 60740-000, Fortaleza, CE - Brasil

E-mail: observatoriodecultura@gmail.com

Recebido em 02 de outubro de 2012.

Revisado pelo autor em 18 março de 2013.

Aceito para publicação em 24 de março de 2013. 